\title{
Derechos de la naturaleza. Ética biocéntrica y políticas ambientales Eduardo Gudynas
}

\author{
Editorial Tinta Limón, Buenos Aires, Argentina, \\ 2015, 317 págs. \\ Beatriz Ensabella \\ Universidad Nacional de Córdoba, Córdoba, Argentina. \\ Email: bettyensabella@gmail.com
}

Este es un libro imprescindible de Eduardo Gudynas, para todos los que desde el campo académico, desde las ONG, desde los movimientos sociales queremos contribuir al debate sobre la naturaleza, los derechos a un ambiente sano y la ampliación de una legítima justicia ambiental.

Este uruguayo ecologista y militante brillante, nos regala un libro de ágil lectura con un prólogo e introducción, 12 partes y un epílogo. La bibliografía que se anexa al final, es abundante, rica, pertinente y sumamente actualizada.

El libro presenta además, fotografías, algunas del propio autor y pictogramas de libre circulación de Iconoclastistas, ilustrativos y cuidadosamente seleccionados. Miembro activo del Centro Latino Americano de Ecología Social (CLAES) a quien agradece por el apoyo en la edición del libro, con una escritura simple pero profunda, nos envuelve y atrapa, y más aún, nos provoca a veces de manera sutil y otras directamente, a contribuir en la defensa y lucha antisistémica por nuestra Madre Tierra. Podría decirse que estas páginas, son un grito de clamor para que se modifique sustancialmente el trato que la humanidad hace de la Naturaleza. Entiende que los derechos de la Naturaleza devienen de encarnar una ética biocéntrica que derive en políticas ambientales más equitativas, de allí el acertado subtítulo de la obra "Ética biocéntrica y políticas ambientales". Como se podrá advertir, se trata de un enfoque "necesariamente transdisciplinario”, como lo dice Gudynas en la introducción.

El libro analiza los derechos de la Naturaleza, vinculando elementos de ecología política, biología de la conservación y ética ambiental. El planteo de la obra, gira alrededor del valor de la Naturaleza, a la cual desmenuza, haciendo un recorrido histórico y en varios planos espaciales, para desembocar en las posturas biocéntricas que sustenta, postulando un mundo con mayor justicia ambiental. Toma como caso, el análisis de la Constitución de Ecuador pero no se restringe a ella, sino que discute los avances y 
contradicciones sobre la valorización de la Naturaleza en los demás países andinos y en general, latinoamericanos.

La cuestión de la valoración es una dimensión de enorme relevancia en los debates ambientales actuales. La crisis ecológica de hoy, es fruto de la presión sobre los ecosistemas en un mundo cuya economía global necesita cada vez más, explotar los recursos propios de cada país. Este extractivismo exacerbado lleva a los límites de sustentabilidad ambiental del planeta y en el fondo de la cuestión está la concepción, mercantilista, utilitaria de la Naturaleza. Una cultura antropocéntrica por la cual solo el hombrees sujeto de valor, lo demás es objeto para ser valorado. Una dicotomía histórica entre Naturaleza y Sociedad por la cual, en busca del desarrollo se justifican los diversos modos de sobreexplotación de la Naturaleza. Esta concepción conlleva a demás, la necesidad de control y manipulación de la Naturaleza. Desde acá queda totalmente anulada la posibilidad de entender la Naturaleza como sujeto de derecho.

“De esta manera enfrentamos un proceso simultáneo en varios frentes: La Naturaleza pierde su organicidad, se la fragmenta y algunos de esos fragmentos tienen un precio y dueños, convirtiéndose en mercaderías” (p. 23). El recorrido histórico que va desde la Conferencia de Estocolmo, pasando por La Carta de la Tierra y otras declaraciones, fueron conformando una ética ambiental que otorgaba valores propios a la Naturaleza e inspiraron a Aldo Leopold “ética de la Tierra” (1966) o la “ecología profunda” del filósofo noruego Arne Naess (1989), el ecofeniminismo, como principales antecedentes del biocentrismo. “... apunta a romper con el antropocentrismo, defendiendo la existencia de valores propios en los seres vivos y en el ambiente. Estos son valores independientes de los intereses y utilidades humanas” (p. 59).

El biocentrismo va más allá de las posturas utilitaristas, donde todas las especies vivientes tienen la misma importancia. Es el reconocimiento del valor inherente de todas las formas de vida. De este modo, la Naturaleza es sujeto de valores, sujeto de derechos. Y en este sentido, se debe avanzar en la discusión de una ética ambiental en relación a una ética social que propenda a una justicia ambiental y ecológica.

“Una vez que se logra el reconocimiento de esos valores intrínsecos, se generan inmediatamente obligaciones, incluso derechos sobre el ambiente y los seres vivos, que deberán ser atendidos por laspersonas, agrupamientos sociales, empresas, el Estado, etc. Desde allí se pueden comenzar a explorar nuevas políticas ambientales construidas desde el respeto biocéntrico” (p. 70).

Una vez que se discute la postura biocéntrica, se realiza una profunda crítica a las concepciones de Naturaleza heredadas de la Modernidad y racionalidad europeas, para luego adentrarse en los avances que logra la nueva Constitución de Ecuador. Lamentablemente, desde la colonización,la Naturaleza quedó separada de la sociedad, conformada por elementos frag- 
mentados que pueden ser estudiados, dominados y controlados. Más aún, la Naturaleza es oferta de recursos para ser explotados.

Frente a estas posturas antropocéntricas y utilitaristas, en la nueva Constitución de Ecuador (2008) se reconoce a la Naturaleza como sujeto de derecho; además, obliga a considerar esos derechos junto a otros, en los debates y la administración de la justicia. En la nueva Constitución, se reubicaron los derechos de tercera generación vinculados al ambiente y se formalizaron los derechos de la Naturaleza, propios de valores intrínsecos. Esto es indudablemente novedoso, pero también, la nueva Constitución del país andino, ofrece una mirada intercultural y renovadas maneras de considerar el desarrollo. Define a la Naturaleza o Pachamama, como aquella "donde se reproduce y realiza la vida" (art. 71), una anclada en las cosmovisiones de los pueblos indígenas, la otra proveniente de la cultura europea. Desde esta concepción hegemónica, hablar de Naturaleza implica la dicotomía con la sociedad, como una de las bases más firmes de la modernidad. Mientras que la perspectiva de la Pachamama, rompe esa dualidad y el hombre es parte del ambiente, y no puede ser entendido sin ese contexto. Equiparar Naturaleza y Pachamama implica colocar en el mismo nivella herencia de conocimiento europeo, con los saberes tradicionales de las comunidades indígenas y campesinas. Asimismo, los derechos ambientales fueron incorporados bajo la perspectiva del Buen Vivir, sumaykawsay en kichwa.

Los derechos de la Naturaleza están expresados en el cap 7, art 71 al 74 y aparecen en el libro en el cuadro 4.1 (págs. 100 y 101). Y luego aclara Gudynas: "Hay al menos tres componentes en el caso de los derechos de la Naturaleza en el contexto constitucional: ético, que legitima un debate sobre los valores que encierra el ambiente no-humano; moral, en tanto se derivan obligaciones tales como asegurar la preservación de la biodiversidad; y político, expresado en aspectos que van desde la sanción de la constitución a la elaboración de un nuevo marco legal” (p. 101).

En la Constitución se otorga además, el derecho a la restauración integral de la Naturaleza o Pachamama. Esto significa que además de las indemnizaciones por daños ambientales, se pone el acento en la propia Naturaleza y que esta debe volver a su estado original previo a un impacto. Asimismo, enlaza con el Buen Vivir, rescatando el diálogo multicultural.

Atendiendo a la necesidad de reconocer a la Naturaleza como sujeto de derechos es necesario promover otra perspectiva, que aquí se denomina justicia ecológica. Esta es una justicia que parte de reconocer a la Naturaleza desde sus valores propios. Es una consecuencia inevitable y necesaria del reconocimiento de la secuencia que comienza con los valores intrínsecos y sigue con los derechos de la Naturaleza. Por otro lado, se mantendrá el rótulo de justicia ambiental para aquella que se basa en los derechos a un ambiente sano o la calidad de vida, descansando en las concepciones clásicas de los derechos ciudadanos. El tránsito hacia una justicia ecológica es necesario ya que la destrucción de plantas y animales no es solo un 
asunto de compasión, sino también de justicia; la desaparición de ecosistemas no arroja solamente problemas económicos, sino que también encierra cuestiones de justicia, y así sucesivamente con buena parte de la problemática ambiental.

El reconocimiento de los valores intrínsecos, los derechos de la Naturaleza y un campo de la justicia ecológica, tienen muy diversas repercusiones en el campo de la política, y cómo se construyen los estilos de desarrollo.En este sentido, el reconocimiento de los derechos de la Naturaleza no impide el uso y aprovechamiento de los recursos naturales, sino que impone condiciones y responsabilidades que deberán ser discutidas. Los valores intrínsecos y derechos de la Naturaleza conllevan una crítica radical a las demandas de crecimiento económico y expansión productivista que sólo son posibles cuando el ambiente es apenas una canasta de recursos. En cambio, la protección de todas las formas de vida, reclamada por el biocentrismo, no puede aceptar el uso exacerbado de materia y energía para sostener estilos de vida opulentos, sino que la Naturaleza debe ser juiciosamente aprovechada para erradicar la pobreza y asegurar una buena calidad de vida. "Es una visión de un desarrollo otro, más austero y enfocado en las personas, y no en el crecimiento económico. Este abordaje se superpone ampliamente con las discusiones actuales sobre alternativas al desarrollo, en especial con corrientes tales como la sustentabilidad superfuerte o las propuestas que invocan la idea del «buen vivir»” (p. 259).

La riqueza de la obra que acabamos de reseñar, además de la claridad y variedad de contenidos conceptuales renovados que expone para el debate, puede ubicarse en la mirada multidisciplinaria con que se van abordando los diversos temas. Además, se articulan los aportes académicos con las prácticas y vivencias de los movimientos sociales, lo cual enriquece las afirmaciones al fusionar teoría y praxis.

Justamente el desafío está puesto en los diversos grupos sociales, particularmente indígenas, movimientos urbanos, ONG que reclaman justicia en todas sus dimensiones clásicas, y al hacerlo desde sus propias culturas, también expresan otra dimensión de la justicia, la de tipo ambiental. Sus expresiones pueden ser muy variadas (a veces son demandas territoriales, otras sobre recursos naturales o contra la contaminación, etc.), pero lo importante es que todas ellas expresan nuevas reivindicaciones y denuncian injusticias que ya no pueden ser atendidas de manera efectiva bajo las facetas actuales de la justicia, sino que es necesario reconocerles sus aristas ecológicas.

Es por esta razón que uno de los principales atributos del biocentrismo expuestos en la obra de Gudynas, es obligar a valorar y pensar desde otros puntos de partida para adentrarnos en caminos que salgan de la Modernidad que colonizó nuestro pensamiento y acciones.

Se trata de una invitación a pensar en una justicia ecológica que nos acerque a los modos de vida comunitarios de las comunidades campesinas 
e indígenas. Es el momento ideal para debatir estos temas, dadas las condiciones de agotamiento del planeta y la preocupación colectiva por el futuro de nuestra Madre Tierra. Intentémoslo, incluyamos estos conceptos, miradas, perspectivas que tan sabiamente propone Gudynas, en nuestras discusiones, abramos el debate a estos temas. Y con esto, algo habremos avanzado en la construcción de un desarrollo alternativo. 
Polis, Revista Latinoamericana, Volumen 15, $N^{\circ}$ 43, 2016

\section{Bibliografía}

Fraser, N. (2008), Escalas de justicia, Herder, Barcelona.

Gudynas, E. (2009), El mandato ecológico. Derechos de la Naturaleza y políticas ambientales en la nueva Constitución, Editorial AbyaYala, Quito.

Ídem (2010) "La senda biocéntrica: valores intrínsecos, derechos de la naturaleza y justicia ecológica” en Tabula Rasa, No.13: 45-71, julio-diciembre, Bogotá, Colombia. 